\section{GHLORAMPHENICOL FROM STREPTOSPORANGIUM VIRIDOGRISEUM VAR. KOFUENSE}

\author{
Atsushi Tamura, Imao Takeda, \\ Shunsuke Naruto \\ and Yoshio Yoshimura \\ Research Laboratories, \\ Dainippon Pharmaceutical Co., Ltd., \\ Suita-shi, Osaka, Japan
}

(Received for publication January 25, 1971)

In a continuing search for less known genera of the Actinomycetales as producers of new antibiotic substances, we noted that chloramphenicol was produced from Streptosporangium viridogriseum var. kofuense $\left(\mathrm{S}_{2}-\right.$ 28), which was isolated from soil and described by Nonomura and OHARA ${ }^{1)}$. This report presents initial data concerning the isolation of chloramphenicol from the streptosporangium.

When the producing strain $\left(\mathrm{S}_{2}-28\right)$ was submerge-cultured in a medium composed of $5 \%$ glycerol and $1.5 \%$ defatted soybean meal ( $\mathrm{pH}$ 6.0), maximum activities against Staphylococcus aureus and Escherichia coli were attained after $48 \sim 72$ hours.

The cultured broth was freed from mycelium and extracted with ethyl acetate at $\mathrm{pH}$ 4.5. The extract was washed with sodium carbonate buffer of $\mathrm{pH} 10$. The ethyl acetate solution of the antibiotic was evaporated to dryness yielding a yellowish brown oily substance, which was then washed with $n$-hexane to remove lipids. The residue was dissolved in a small volume of ethanol and precipitated by adding ten parts of $n$-hexane. From 50 liters of cultured broth, $3 \mathrm{~g}$ of crude crystals were isolated. They were further recrystallized from a mixture of ethanol and $n$-hexane.

Colorless needles or elongated plate crystals were obtained. The crystallized substance was identified as chloramphenicol, $\mathrm{D}(-)$-threo-1-p-nitrophenyl-2-dichloroacetamido-1,3-propandiol, on the basis of the following data:

$$
\text { Analysis, found: } \quad \mathrm{C} 40.74, \mathrm{H} 3.55 \text {, }
$$

$\mathrm{N} 8.64, \quad \mathrm{Cl} 21.97$

Calcd. for $\mathrm{C}_{11} \mathrm{H}_{12} \mathrm{O}_{5} \mathrm{~N}_{2} \mathrm{Cl}_{2}$ : C 40.88, H 3.74, $\mathrm{N} 8.67, \quad \mathrm{Cl} 21.95$

m.p. $152 \sim 154^{\circ}$ (dec.). No depression when mixed with chloramphenicol.

$[\alpha]_{\mathrm{D}}^{27}-25.4^{\circ}$ (c 1.07, ethyl acetate).

$[\alpha]_{\mathrm{D}}^{27}+15.5^{\circ}$ ( $c$ 0.915, ethanol).

TLC on silicagel, solvent systems chloroform - methanol (95:5) and ethyl acetate: $\mathrm{Rf}$ identical with chloramphenicol.

UV spectrum (in water): $\lambda_{\max } 280 \mathrm{~m} \mu$ $(\log \varepsilon$ 3.97).

IR spectrum (in $\mathrm{KBr}$ disk) and NMR spectrum (in $\mathrm{DMSO}-\mathrm{d}_{6}$ solution): identical with chloramphenicol.

Acknowledgement

The authors express deep thanks to Assistant Professor H. Nonomura, Faculty of Engineering, Yamanashi University for the supply of the $\mathrm{S}_{2^{-}}$ 28 strain.

\section{Reference}

1) Nonomura, H. \& Y. Ohara: Distribution of Actinomycetes in soil. VII. A culture method effective for both preferential isolation and enumeration of Microbispora and Streptosporangium strains in soil. 2. Classification of the isolates. J. Ferment. Tech. $47: 701 \sim 709,1969$ 